\title{
NDCX-II PULSED POWER SYSTEM AND INDUCTION CELLS*
}

\author{
W.L. Waldron, L.L. Reginato, M. Leitner \\ Lawrence Berkeley National Laboratory, 1 Cyclotron Rd., MS 47-112 \\ Berkeley, CA 94720
}

\section{Abstract}

The Heavy Ion Fusion Science Virtual National Laboratory (HIFS-VNL) is currently finalizing the design of NDCX-II, the second phase of the Neutralized Drift Compression Experiment, which will use an ion beam to explore Warm Dense Matter (WDM) and Inertial Fusion Energy (IFE) target hydrodynamics. The ion induction accelerator will include induction cells and Blumleins from the decommissioned Advanced Test Accelerator (ATA) at Lawrence Livermore National Laboratory (LLNL). A test stand has been built at Lawrence Berkeley National Laboratory (LBNL) to test refurbished ATA induction cells and pulsed power hardware for voltage holding and ability to produce various compression and acceleration waveforms. The performance requirements, design modifications, and test results will be presented.

\section{INTRODUCTION}

The first phase of the Neutralized Drift Compression Experiment (NDCX-I) has successfully demonstrated simultaneous radial and longitudinal compression using a technique of imparting a velocity ramp on the ion beam, letting the beam drift through a neutralizing plasma to offset space-charge forces, and applying a high solenoidal field before the target. ${ }^{1,2}$ To provide sufficient energy deposition over a time period less than the hydrodynamic expansion time, neutralized drift compression has been developed to produce $\sim 1 \mathrm{~ns}, \sim 1 \mathrm{~mm}$ diameter beams from longer beams with modest energy. NDCX-I has provided a beam for initial target experiments and diagnostic development. NDCX-II has been developed to increase the beam energy so that $\sim 1 \mathrm{eV}$ temperatures can be produced for WDM experiments. 3,4

\section{NDCX-II DESCRIPTION}

NDCX-II is a funded project to build a $3-3.5 \mathrm{MeV}$ induction accelerator for a lithium beam at LBNL. The induction cells and Blumleins to drive the induction cells will be reused from ATA at LLNL. ${ }^{5}$ Additional custom pulsers will be required to drive the induction cells at the lower energy end of the accelerator where the beam pulse widths are longer than the 70 ns FWHM Blumlein pulse. Physics designs for the project have been developed using acceleration and compression waveforms produced from a simple circuit model. ${ }^{6,7}$ A candidate design is shown in Figure 1 where the voltage waveforms on 34 acceleration gaps are illustrated.

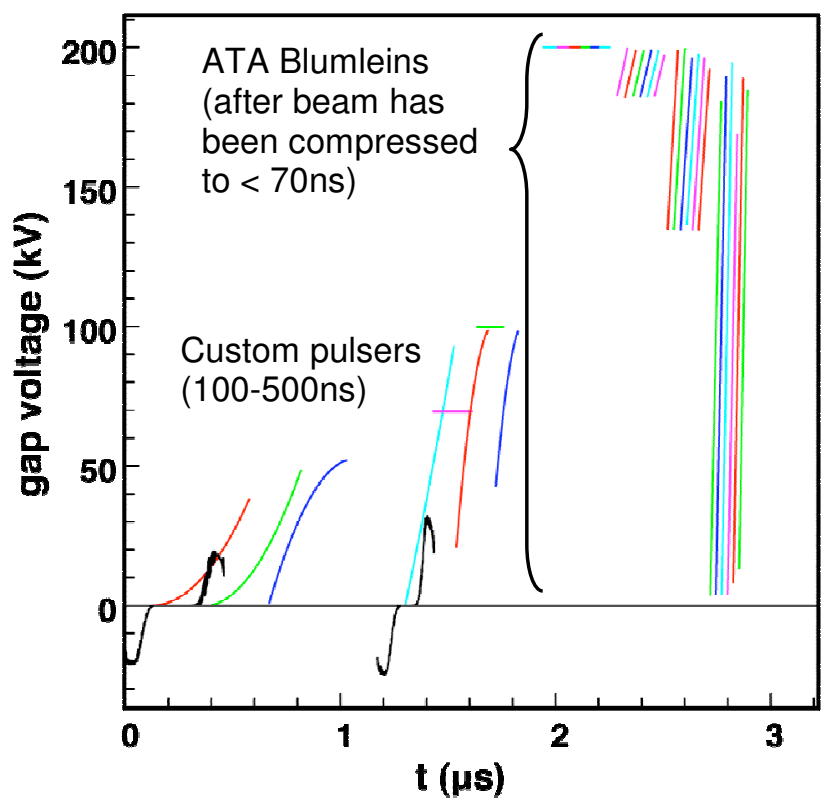

Figure 1. NDCX-II acceleration and compression waveforms for a candidate physics design. The transit time of the beam to the end of the accelerator is $\sim 3$ us.

\section{INDUCTION CELLS}

The original ATA induction cells were designed for an electron beam and included a $0.3 \mathrm{~T}$ DC solenoid. The NDCX-II ion beam requires much stronger transverse focusing, so the original solenoid will be replaced with a 3 $\mathrm{T}$ pulsed solenoid (Figure 2). This modification introduces the possibility of saturating the ferrite of the induction cell with the return flux of the high field

\footnotetext{
* This work was supported by the Director, Office of Science, Office of Fusion Energy Sciences, of the U. S. Department of Energy under Contract \# DE-AC02-05CH11231.
} 
solenoid. The original plan was to run the solenoids in the same direction to minimize the return flux which comes up between cells and into the ferrite. Unfortunately, the eddy currents induced in the cell housing force all of the return flux directly into the ferrites. This effect has been observed on the test stand tested and will require a significant modification to the cell (see Figure 4). The size of the cavity which holds the solenoid will have to be increased to include a bucking coil, copper flux excluder, or a laminated iron flux return. Electromagnetic modeling will determine the optimized geometry and a prototype cell will be built and tested.

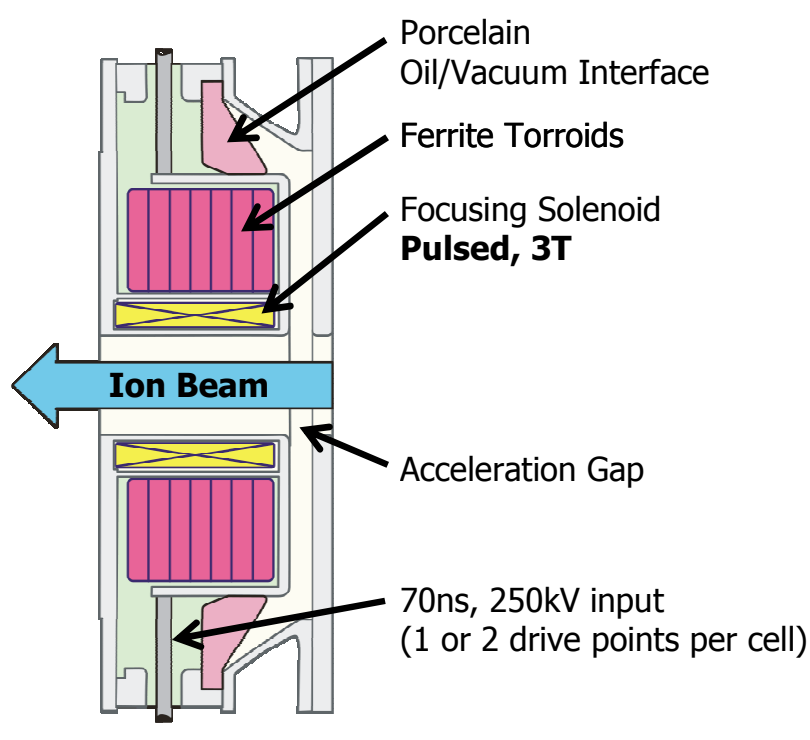

Figure 2. ATA induction cell with $3 \mathrm{~T}$ pulsed solenoid for NDCX-II.

\section{PULSED POWER SYSTEM}

The pulsed power system will use a thyratron switch chassis which has a $2.5 \mathrm{uF}$ capacitor and charges a $70 \mathrm{~ns}$, $12 \mathrm{ohm}$ Blumlein to $200 \mathrm{kV}$ through a 1:10 step-up transformer. This is the original ATA pulsed power system, except that the switch chassis will be DC charged. ATA used a command resonant charging system to support a $1 \mathrm{kHz}$ burst mode. The maximum repetition rate for NDCX-II will be 1 shot per 10 seconds.

Each Blumlein spark gap will be triggered with a dedicated $100 \mathrm{kV}$ trigger generator for complete timing flexibility. ATA used a Blumlein output which fanned out to trigger many Blumleins with a $150 \mathrm{kV}$ trigger at almost the same time since the beam transit time between cells for the relativistic electron beam was easy to insert using cable delays.

ATA had an impedance matched system where the 12 ohm Blumlein fed two parallel 24 ohm oil-filled transmission lines and the $10 \mathrm{kA}$ beam and $10 \mathrm{kA}$ resistive load matched the impedance at $250 \mathrm{kV}$. For NDCX-II, there will be a significant impedance mismatch as a result of the shaping networks to generate the ramped compression waveforms from the Blumlein and a configuration which only uses one of the oil-filled transmission lines. One transmission line has been proposed to simplify installation when there are already other significant sources of impedance mismatch in the system. There is also no significant beam loading. To increase the safety margin for voltage holding under these mismatched conditions, the peak cell voltage has been derated from $250 \mathrm{kV}$ to $200 \mathrm{kV}$.

\section{TEST STAND}

A test stand has been built which can accommodate two Blumleins and two induction cells (Figure 3). This test stand will be used to evaluate the refurbished and modified ATA pulsed power and induction cell hardware. The refurbishment activities include disassembling the hardware, cleaning the parts, replacing seals and some insulators, and reassembling. The modifications include replacing the $0.3 \mathrm{~T}$ DC solenoid in the induction cell with a $3 \mathrm{~T}$ pulsed solenoid.

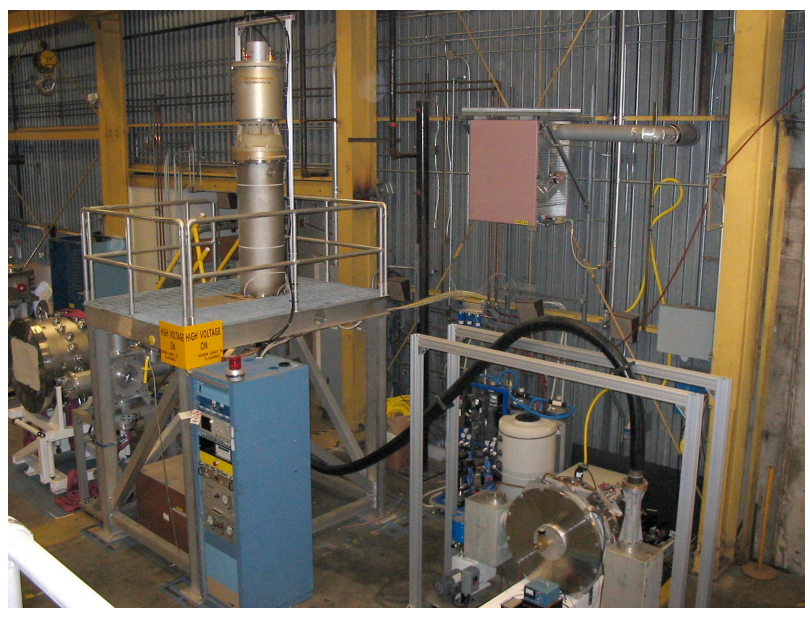

Figure 3. Test stand showing one Blumlein and one induction cell.

After a prototype magnet was installed and tested in an ATA cell, it was clear that the pulsed field from the magnet was saturating some of the ferrite and reducing the available volt-seconds (Figure 4). This effect was significant and will lead to further cell modifications which were mentioned earlier to protect the ferrite from the pulsed solenoid magnetic field. 


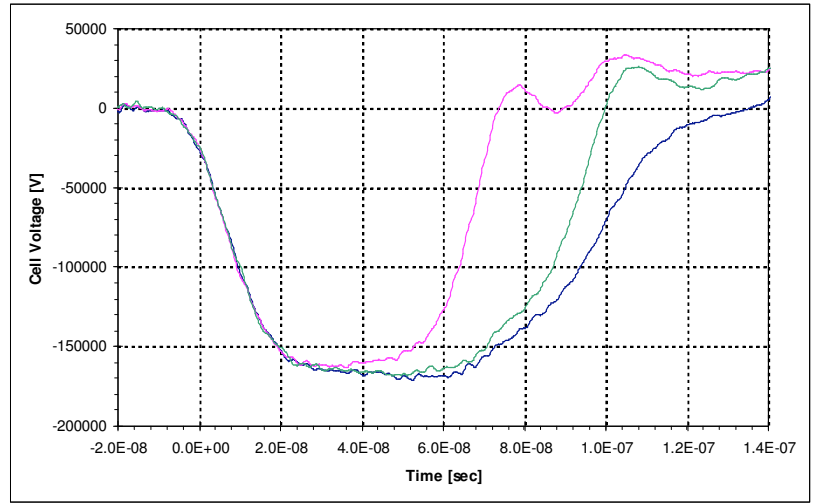

Figure 4. Cell voltage waveforms showing the decrease in ferrite volt-seconds as a function of pulsed magnetic field on the solenoid. The blue trace is without pulsing the solenoid. The green trace is with a $0.5 \mathrm{~T}$ field from the solenoid. The magenta trace is with a $1 \mathrm{~T}$ field from the solenoid.

Subsequent tests have focused on generating the waveforms used in the NDCX-II physics design. From the Blumleins, the two categories of required pulses are flat tops and linear ramps. The flat top pulses generated to date are as expected from ATA documentation (Figure 5). One difference is that the impedance mismatch by using one transmission line and a $24 \mathrm{ohm}$ resistive load at the cell does cause high amplitude voltage reversal which can cause late time vacuum insulator flashovers (Figure 6). The useful part of the ramped waveform should meet the requirements, but this waveform also shows high amplitude late time voltage reversal (Figure 7). This waveform was generated by a $50 \mathrm{ohm}$ resistive load and a $0.8 \mathrm{nF}$ capacitive load at the cell.

After there is confidence in the ability to generate the required waveforms for NDCX-II and the circuit modeling efforts have been baselined, testing will continue to characterize voltage holding and timing jitter.

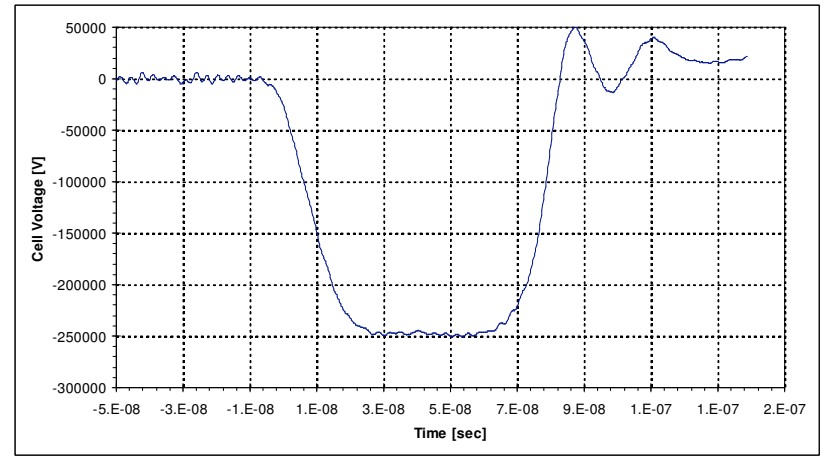

Figure 5. $250 \mathrm{kV}$ flat top waveform with 70 ns FWHM pulse width.

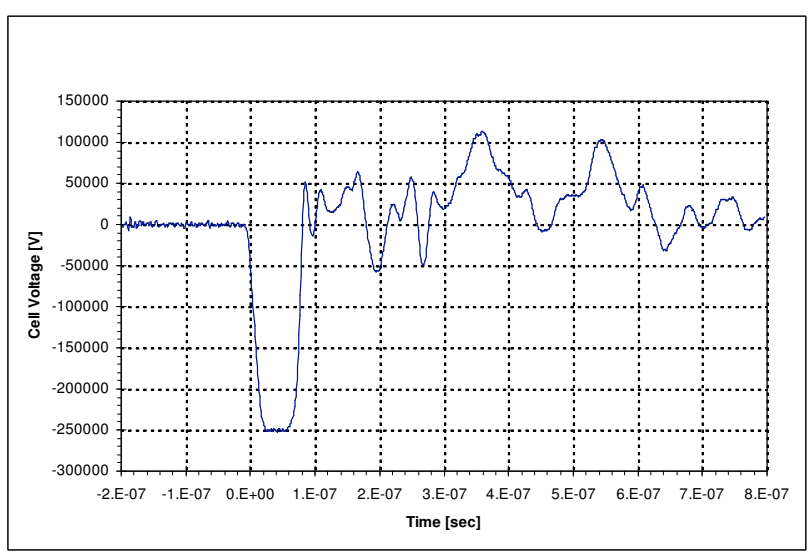

Figure 6. $250 \mathrm{kV}$ flat top waveform showing late time high amplitude voltage reversal.

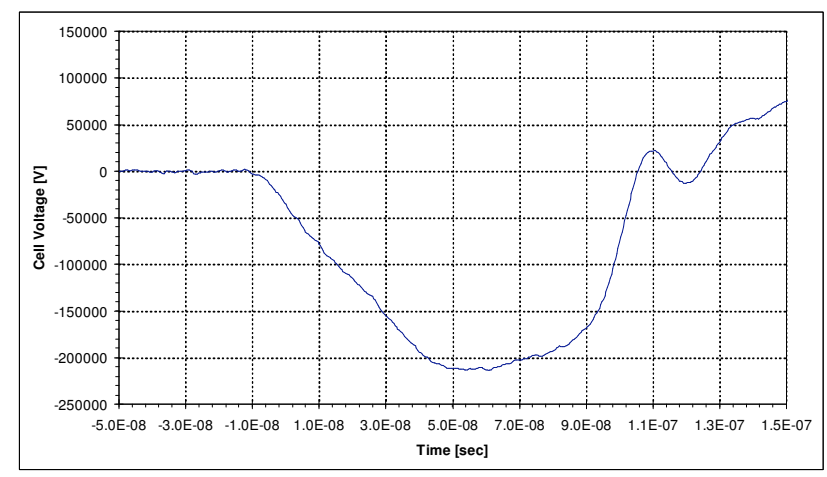

Figure 7. Ramped waveform required for longitudinal beam compression and acceleration.

\section{CONCLUSIONS}

The NDCX-II project has been funded to start in July 2009 and will have a duration of 3 years. The project relies heavily on the induction cells and Blumleins from the decommissioned ATA accelerator, but does require some significant modifications. A test stand has been built to test these modifications as well as timing jitter, voltage holding, and voltage waveform shaping. Initial results on voltage waveform shaping are encouraging, but a circuit model needs to be developed and voltage holding concerns because of large voltage reversal need to be addressed.

\section{ACKNOWLEDGEMENTS}

The authors would like to acknowledge the technical support of Ahmet Pekedis, Tak Katayanagi, and Tom Lipton on the test stand activities. 


\section{REFERENCES}

[1] P.K. Roy, et al., "Drift Compression of an Intense Neutralized Ion Beam," Phys. Rev. Lett., vol. 95, 234801, 2005.

[2] J.E. Coleman, et al., "Bunching and Focusing of an Intense Ion Beam for Target Heating Experiments," Proc. 2007 Particle Accelerator Conference, Albuquerque, NM, June 25-29, p. 3516, 2007, http://www.jacow.org.

[3] L.R. Grisham, "Moderate Energy Ions for High Energy Density Physics Experiments," Phys. Plasmas, vol. 11, p. 5727, 2004.

[4] F.M. Bieniosek, et al., "High Energy Density Physics Experiments with Heavy Ion Beams," Proc. $17^{\text {th }}$ Int. Symp. Heavy Ion Inertial Fusion, Tokyo, Japan, August 4-8, 2008, Nucl. Instr. and Meth. A., vol. 606, issues 1-2, pp. 146-151, July 2009.

[5] L.L. Reginato, "The Advanced Test Accelerator (ATA), A 50-MeV, 10-kA Induction LINAC", IEEE Trans. Nucl. Sci., vol. 30, no. 4, part 2, pp. 2970-2974, Aug. 1983.

[6] A. Friedman, et al., "Toward a Physics Design for NDCX-II, an Accelerator for Warm Dense Matter and HIF Target Physics Studies," Proc. 17 ${ }^{\text {th }}$ Int. Symp. Heavy Ion Inertial Fusion, Tokyo, Japan, August 4-8, 2008, Nucl. Instr. and Meth. A., vol. 606, issues 1-2, pp. 6-10, July 2009.

[7] W. Sharp, et al., "Developing Acceleration Schedules for NDCX-II," Proc. $17^{\text {th }}$ Int. Symp. Heavy Ion Inertial Fusion, Tokyo, Japan, August 4-8, 2008, Nucl. Instr. and Meth. A., vol. 606, issues 1-2, pp. 97-101, July 2009. 